\title{
A Data Science Analysis of Academic Staff Workload Profiles in Spanish Universities: Gender Gap Laid Bare
}

\author{
Ismael Cabero $^{1}$ (D) and Irene Epifanio ${ }^{2, *(D)}$ \\ 1 Department d'Educació i Didàctiques Específiques, Universitat Jaume I, 12071 Castelló, Spain; icabero@uji.es \\ 2 Department de Matemàtiques and Institut Universitari d'Estudis Feministes i de Gènere, Universitat Jaume I, \\ 12071 Castelló, Spain \\ * Correspondence: epifanio@uji.es
}

Citation: Cabero, I.; Epifanio, I. A Data Science Analysis of Academic Staff Workload Profiles in Spanish Universities: Gender Gap Laid Bare. Educ. Sci. 2021, 11, 317. https:// doi.org/10.3390/educsci11070317

Academic Editor: James Albright

Received: 7 June 2021

Accepted: 23 June 2021

Published: 25 June 2021

Publisher's Note: MDPI stays neutral with regard to jurisdictional claims in published maps and institutional affiliations.

Copyright: (c) 2021 by the authors. Licensee MDPI, Basel, Switzerland. This article is an open access article distributed under the terms and conditions of the Creative Commons Attribution (CC BY) license (https:// creativecommons.org/licenses/by/ $4.0 /)$.

\begin{abstract}
This paper presents a snapshot of the distribution of time that Spanish academic staff spend on different tasks. We carry out a statistical exploratory study by analyzing the responses provided in a survey of 703 Spanish academic staff in order to draw a clear picture of the current situation. This analysis considers many factors, including primarily gender, academic ranks, age, and academic disciplines. The tasks considered are divided into smaller activities, which allows us to discover hidden patterns. Tasks are not only restricted to the academic world, but also relate to domestic chores. We address this problem from a totally new perspective by using machine learning techniques, such as cluster analysis. In order to make important decisions, policymakers must know how academic staff spend their time, especially now that legal modifications are planned for the Spanish university environment. In terms of the time spent on quality of teaching and caring tasks, we expose huge gender gaps. Non-recognized overtime is very frequent.
\end{abstract}

Keywords: academia; gender; housework time; Spanish universities; working hours; work-life balance

\section{Introduction}

As [1] points out, the significance of the management and administration of higher education institutions is so relevant that it conditions aspects of life, such as lifestyle and parenting patterns, worldviews, mindsets, aspirations, and motivation, and it is a challenge to meet the expectations of the new generation of students and teachers [2]. On the other hand, the role of universities in the precarization of professional work and the precarization of academics is discussed by Reference [3]. Within the space of management and administration of higher education institutions, there is no one-size-fits-all approach, as there are countless factors that could change the governance model and, thus, the processes that shape the faculty [4]. In this paper, we center on the analysis of the Spanish academic staff workload in order to shine light on their situation and help policymakers make important decisions.

Under Spanish law, the working time of academic staff is restricted to $37.5 \mathrm{~h}$ per week for all full-time staff, since many of them are government employees. The number of hours worked by university staff in the U.S. is much higher than the hours stipulated in the agreement [5]. Do Spanish academic staff work more hours than those stipulated, as happens in the U.S., or is the myth that Spanish government employees work few hours true? Spanish academic staff do not record their working hours on a daily basis as other government employees do, so there are no official statistics. No previous study has addressed this issue in Spain.

There is no previous detailed time allocation workload knowledge study in Spanish universities. How academic staff spend their time has major implications for the faculty, students and their institutions. The distribution of the number of hours worked depends on many factors, such as gender [6], staff category, type of institution, etc. [7]. 
O'Meara et al. [7] conclude that women spend more time on teaching-related activities, and men spend more time on research in research universities. This is also the conclusion reached by Reference [8] for Spanish scientists, but no data about this are shown, i.e., we do not know how many hours are spent on each activity, neither do we know the difference between men and women in this respect.

Housework is an academic issue $[9,10]$. The traditional lack of co-responsibility of men in domestic tasks and caring for other people facilitates the possibility of success in this environment, as more time can be dedicated to other activities. In Spain, there are some laws on public institutions' obligation to implement egalitarian policies. However, in practice, there is a lack of compliance with many points of the law [11]. Universities maintain inequalities in the field of university work [12,13]. The tendency to divide and focus on different tasks maintains the roles and routines of interaction within universities [14-17], which are gendered bureaucratic structures [18]. According to References [19-22], the greater involvement of women in teaching and university services could be a way of intervening in gender policy programs. All these gender inequalities give rise to a gender wage gap in Spanish universities [23]. Ref. [23] conclude that the gender pay gap is more intense in the case of mothers, and the gap is not the result of a difference in merits between academic women and men, but rather of the operating structure of the universities and the general social structure.

Today, legislative changes are planned for Spanish universities, among other things in terms of professional categories. In order to make important decisions, policymakers must know the present workload and how it is distributed according to different factors, such as gender, age, or the current professional categories. One of the papers that is most closely related to our work is that of Allen [24], which studied workload differences by institution and ethnicity in the United States. However, the Spanish university system is completely different; for example, there are not different types of public universities in Spain or clear ethnic groups among Spanish university staff, except very few exceptions. Allen [25] instead studied mainly workload differences by gender, which is more in line with our objective.

Our objective is to carry out an exploratory study of the time distribution of academic work, i.e., paid work and unpaid work (domestic and caring tasks), among Spanish academic staff. Having a snapshot of Spanish academic staff may be very useful when making the mandatory gender impact assessment for changing laws, policies, or programs. In this way, legislation and policies can be better designed or transformed to prevent a negative impact on gender equality and to proactively promote gender equality.

However, we find differences between our proposal and the work presented by Allen [25] and others in studies of faculty workload and time use. Unlike Allen [25], our work refers to Spanish universities rather than universities in the United States. Note also that the data in Allen [25] are from more than 25 years ago (from the 1990s), so it is possible that things may have changed over time. Furthermore, many studies of faculty workload use cross-sectional national surveys that ask participants to estimate their time use in broad categories over the last year or semester. This is not an easy task since it requires an extensive memory exercise. We limited ourselves to asking about the activities of the last week, and we propose more detailed categories.

On the other hand, other works use different approaches to study gender differences in academics in various aspects, such as semi-structured interviews [26] for time use, or even pictures [27] for representing academic careers. Instead, we use data from a statistical survey with more detailed activities than those asked about in Allen [25], as mentioned above. Although finer details can be found using a time-diary method, as in O'Meara et al. [7], who record the activities in 5-min increments over 4 weeks, so many details can be excessive. In fact, $\mathrm{O}^{\prime}$ Meara et al. [7] only show the results of a few activities, but we do not see a complete picture of the situation. Furthermore, a time-diary method is very time-consuming for the respondents, which can make the results more biased, as may only 
be completed by the more involved participants. This is the reason why we decided to carry out a statistical survey that can be answered in $10 \mathrm{~min}$.

Furthermore, our work is also original because of the statistical analysis carried out. We do not just show the mean, as is usual, but we also show the five-number summary, which is better for skewed distributions or those containing outliers, as is the case with this kind of data. In this way, we discover a better picture, which would remain hidden if only the mean was shown. Not only that, but we also carry out a multivariate statistical analysis beyond the typical disaggregation of the descriptive statistics by different factors. We use innovative statistical learning techniques (clustering techniques and archetypal analysis), which give us the academic staff workload profiles and to the best of our knowledge is the first time they have been applied to this topic.

\section{Materials and Methods}

We used the questionnaire created with Google forms that is available at https:/ forms.gle/XCFHZqzYao19KdPz5 (accessed on 24 June 2021) and translated into English at http:/ / www3.uji.es/ epifanio/RESEARCH/Questions.pdf (accessed on 24 June 2021). It was administered as a web-based instrument. Before conducting the main survey, we did a small pilot study in the department of one of the authors in order to detect whether there are any possible difficulties with the meaning of some questions or completion of the form, etc. We asked them to inform us of any problem, but no difficulty was reported.

The questions follow a similar formulation to some of the questions included in the National Study of Post-secondary Faculty (https:/ /nces.ed.gov/surveys/nsopf/ (accessed on 24 June 2021)) used by Allen [25], but questions are asked about time devoted to more activities. On the one hand, we are aware that raw measures, such as weekly time devoted to teaching, research, etc., cannot capture the qualitative aspects of academic work, but on the other hand, numbers can also give us a picture of what is happening and can be more clearly understood by policymakers.

We are also aware that the weekly schedule can vary a lot depending on the semester and even on the week. This is why we specified at the beginning of the questionnaire that people should refer to what they did in a standard week. We suggest considering what they did the previous week if that week was a standard week, i.e., without any unusual event. We use the whole week from Monday to Sunday as a timescale and not just weekdays, since it is well-known that many academics also work during weekends. We also consider weeks in the middle of a semester for launching the survey.

The first part of the questionnaire contains personal questions, while the second part, i.e., the numbered questions, covers questions devoted to estimating the time spent. The survey required the Professional Category; Academic disciplines; Gender; Age; and Number of children.

In Spain, there are different types of staff, including part-time staff and full-time staff. The part-time staff are called Personal Asociado (AS) and they also work outside the university. Their main tasks should only be teaching-related. Regarding the fulltime staff, there are temporary and permanent staff. The temporary staff may or may not be doctors (the majority are), and they are called Personal Ayudante Doctor (AYD) or Personal Ayudante (AY), respectively. There is also a temporary figure called a Visitante $(V I)$, which is not very common in the majority of universities. Some of the permanent staff have an employment contract, while others are government employees. Those who are permanent with a contract are called Personal Contratado Doctor (CD) (the majority), although there is a minority belonging to Personal Colaborador (CO), who are not usually doctors and whose contract results from a previous law. There are mainly two categories of government employees: Profesorado Titular de Universidad (TU) and Profesorado Catedrático de Universidad ( $\mathrm{CU}$ ), which would be equivalent to Associate Professor and Full Professor. $\mathrm{CD}$ could be seen as a similar category to TU. Furthermore, there are a few government employees, who are not usually doctors, called Profesorado Titular de Escuela Universitaria (TEU), a category that results from a previous law. Finally, some categories are mainly 
research figures: predoctoral fellows (PRE) and postdoctoral fellows (POST), or mainly teaching figures: staff who cover substitutions when academic staff are on leave, called Personal Sustituto (SU).

\subsection{Data Collection}

We would have liked to use a stratified sampling technique for randomly selecting academic staff, but we did not have access to the database of Spanish academic staff. In early 2019, we asked the Vice-Chancellors of several Spanish public universities for permission to send an email with the link to the questionnaire to all the academic staff of their universities. Only Jaume I University accepted it, as long as we followed its protocol. Therefore, we presented the request to the Research Ethics Committee at Jaume I University, and we received its approval in June 2019.

Given the refusal of most universities to allow us to send the questionnaire by email to all their academic staff, we looked for the public email contact of each Department of 10 Spanish universities. Therefore, we sent an email to the administrative staff of each department and kindly asked them to forward the questionnaire to the academic staff in their departments. This data collection occurred in March and April 2019, in the middle of the second semester of the 2018/2019 academic year. We cannot know the percentage of non-responses, since we do not know which administrative staff decided to forward the email to the academic staff of their department and which did not. Therefore, we do not know if non-responses are because they did not want to respond to the questionnaire or because they simply did not receive our invitation to answer the questionnaire.

The second data collection occurred in October 2019, in the middle of the first semester of the 2019/2020 academic year, when an email to all the academic staff of Jaume I University (UJI) was sent by its Communication Service. In this email, the office of the Vice-Chancellor of Research and Transfer invited the academic staff to complete the questionnaire, which was approved by the Ethics Committee. Only one email was sent to the academic staff and no reminder was sent to answer. Two hundred and twenty-seven academics responded from a total of 1542 academic staff at Jaume I University in the 2019/2020 academic year (https:/ / www.uji.es/institucional/uji/presentacio/xifres/ (accessed on 24 June 2021)), i.e., $15 \%$ replied. Note that our response rate of $15 \%$ is much higher than the $2 \%$ response rate reported by O'Meara et al. [7], where they invited 6438 faculty staff, but only 111 participated. In fact, our response rate is $22 \%$ if we only consider the full-time teaching staff of UJI (AY, AYD, CD, CU, TU, TEU).

We joined the data from the first and second collection and the total number of responses obtained was 711 . However, from the initial 711 responses, we discarded 8 because of missing or impossible answers. Therefore, the final number of participants was 703 .

The demographics of the participants are generally comparable to nationwide statistics of Spanish academic staff [28]. The participants consisted of 356 (51\%) women and $347(49 \%)$ men, while the Spanish female faculty represents $41 \%$. Therefore, more women replied to our invitation. Table 1 compares the percentage of participants and the population, according to professional category. However, we do not know the number of PRE, POST and SU personnel in Spanish academic staff, so the percentages are computed without considering those categories or the 'Other' category. The percentage is quite similar except for AS, which has the greatest discrepancy. The percentage of AS in the sample is smaller than in the population. Remember that AS are part-time personnel whose main job is outside the university, so some of them may not be very willing to answer university surveys. On the contrary, the group that compensates for the lower response from AS is $\mathrm{TU}$, which is the largest group of full-time teachers, with a percentage in the sample that is higher than in the population. AYD is also a group with a slightly higher percentage of responses in the sample. This could be explained by the fact that the UJI sample represents $32 \%$ of the sample, and the percentage of AYD at UJI is higher than in many Spanish 
universities. For the rest of the categories, the population and sample percentages are quite similar.

Table 1. Percentage distribution of faculty staff for the population (Spanish academic staff) and the sample according to category.

\begin{tabular}{ccccc}
\hline & \multicolumn{2}{c}{ Population } & \multicolumn{2}{c}{ Sample } \\
Category & Number & Percentage & Percentage & Number \\
\hline CU & 10,017 & 10.9 & 12.4 & 81 \\
TU & 28,057 & 30.5 & 40.0 & 260 \\
TEU & 4284 & 4.7 & 2.8 & 18 \\
AY & 575 & 0.6 & 0.5 & 3 \\
AYD & 3223 & 3.5 & 10.9 & 71 \\
CD & 11,347 & 12.3 & 14.5 & 95 \\
AS & 31,550 & 34.3 & 18.8 & 123 \\
CO & 2026 & 2.2 & 0 & 0 \\
VI & 903 & 1 & 0.5 & 3 \\
PRE & & & & 24 \\
POST & & & & 18 \\
SU & & & & 2 \\
Other (not specified) & & & &
\end{tabular}

Table 2 compares the percentage of participants and the population, according to academic discipline. Note that they are very similar, except in Health Sciences and Engineering and Architecture. It is not surprising that the percentage of academic staff in Health Sciences in the sample is lower than in the population since the percentage of AS in this branch is the highest due to Health Sciences AS personnel, and the part-time staff responded less than the full-time staff. Note also that the lowest percentage of AS occurs in Engineering and Architecture. For example, at UJI, AS personnel account for $72 \%$ of the academic staff in Health Science, $46 \%$ in Arts and Humanities, $41 \%$ in Social and Legal Sciences, and 19\% in Engineering and Architecture [29].

Table 2. Percentage distribution of faculty staff for the population (Spanish academic staff) and the sample, according to academic discipline.

\begin{tabular}{ccccc} 
Academic & \multicolumn{2}{c}{ Population } & \multicolumn{2}{c}{ Sample } \\
Discipline & Number & Percentage & Percentage & Number \\
\hline Arts and Humanities & 14,566 & 12.1 & 15.4 & 108 \\
Sciences & 18,057 & 15 & 15.9 & 112 \\
Health Sciences & 23,354 & 19.4 & 12.1 & 85 \\
Social and Legal Sciences & 39,606 & 32.9 & 30.1 & 212 \\
Engineering and Architecture & 24,799 & 20.6 & 26.5 & 18 \\
\hline
\end{tabular}

\subsection{Limitations}

We have previously mentioned the obstacles we encountered when collecting the data. Therefore, the main limitation to this research is the selection of participants, which was not randomized. Participants were self-selected, so it is a voluntary response sample. This can produce bias. Therefore, we cannot use inferential statistics. Our study is strictly exploratory and we only use descriptive statistics.

Note that our questionnaire is not about a controversial topic, such as substance abuse or sexual behavior, where people may want to hide bad behaviors, and the impact of non-response bias could be really important [30]. Although the response rate of our survey is low (22\% in Jaume I University for full-time teaching staff), according to $\mathrm{O}^{\prime} \mathrm{Meara}$ et al. [7], faculty responses to national surveys are typically around $25-35 \%$, so it is within the usual range and is higher than the $2 \%$ response rate reported by O'Meara et al. [7]. Nevertheless, non-response bias is not determined by the response rate, but by the reasons for nonparticipation. A low response rate does not necessarily indicate non-response bias [31]. 
In fact, Reference [32] assessed response bias in a web survey at a university faculty and suggests that response bias was undetectable.

Several works have studied non-response bias [33], and three approaches are considered. One of them is the comparison of the demographics of respondents versus non-respondents, which we have done in the previous section, and we have seen that they were not very different. Another approach is comparing the responses of participants who answered different waves ("reminders") of the survey, but this option was not possible in our case. And the third approach is about the utility of subjective estimates of non-response bias. In our case, faculty staff with a high workload may be more willing to participate. But, in any case, this allows us to gather information to detect problems and patterns. The exact extent of the problems identified can be further determined with random samples in future research.

Despite the limitations, this study offers a unique portrait of Spanish faculty workload and a way to expose their problems and the different profiles, with a detailed time allocation workload that is not presented in other more meticulous works based on structured observations [34] and interviews [35], where samples are not random and the sample size is very small (up to 30 voluntary participants). Thus, this work provides a novel and important contribution to the way the academic workload is analyzed.

\subsection{Data Cleansing and Preparation for Machine Learning}

We cleaned up the data in order to correct or remove inaccurate data. As mentioned above, five individuals were completely removed since their answers to the questions were either impossible or extremely incomplete. When checking the accuracy of the data, we also detected some corrupt data and impossible answers for certain questions. In some cases, they could be corrected. For example, a few subjects answered the weekly hours of sleep instead of the average daily hours of sleep. In other cases, we were not be able to guess the reason for the misleading data, so the corrupt data point was removed, and we treated it as a missing data point. Categorical answers to numerical questions were also treated as missing data. For instance, a few people answered 'a lot of hours' instead of a particular number of hours. After this cleaning process, the maximum number of missing data in one question was 20 out of 703 . In total, there were 107 missing data in the whole data set, which only represents $0.8 \%$ of the data set, i.e., the percentage of missing values was very low.

Although we could simply delete the complete case, this way of handling missing data has many disadvantage since a great deal of useful information is discarded. Therefore, in order to carry out the statistical analysis, and especially the multivariate statistical analysis, we use an advanced way of handling missing data. We consider imputation. We apply the aregImpute function in the R package Hmisc [36], which uses additive regression, bootstrapping, and predictive mean matching to carry out the imputation. In this way, the missing data are replaced by an estimated value, which is computed by a prediction based on the observed values of that variable and the other variables.

\section{Results and Discussion}

In this section, descriptive statistics disaggregated by different factors are presented and discussed. Besides the classical mean and standard deviation (Sd), we also show the five-number summary, which is better for skewed distributions or those containing outliers, as is the case with this kind of data. In other words, we also show the percentiles $0 \%$ (the minimum value), $25 \%$ (first quartile), 50\% (the median), $75 \%$ (the third quartile), and $100 \%$ (the maximum value), in addition to the interquartile range (IQR), which is a more robust measure of variability than $\mathrm{Sd}$. We also show the number of individuals in each cell in the 'Count' column.

Table 3 shows the distribution of hours per week of academic work by gender, i.e., it collects the addition of the hours from questions 1 to 8 of the questionnaire for full-time staff, i.e., without AS. The 'Global' row contains the summary statistics of both men and 
women. Note that the average number of weekly working hours of academic staff in the sample is $49.0 \mathrm{~h}, 11.5 \mathrm{~h}$ more than the stipulated $37.5 \mathrm{~h}$ (which is equivalent to $7.5 \mathrm{~h}$ per day). These $11.5 \mathrm{~h}$ represent more than one and a half extra days of work per week. We have computed the quantile corresponding to $37.5 \mathrm{~h}$ and $80 \%$ of the academic staff in the sample work more than $37.5 \mathrm{~h}$. There is a high degree of variability in the distribution, with a difference of $17 \mathrm{~h}$ between the $75 \%$ of staff that work the most hours and the $25 \%$ that work the fewest hours, although the latter work $40 \mathrm{~h}$. Furthermore, $50 \%$ of the sample work more than $47 \mathrm{~h}$, i.e., more than one extra day of work per week, while $25 \%$ of the sample work more than $57 \mathrm{~h}$ per week, i.e., more than two extra days of work per week. More than $20 \%$ of the staff in the sample work more than $60 \mathrm{~h}$ per week, i.e., more than three extra days per week. In regard to gender, women work $3.4 \mathrm{~h}$ per week on average more than men.

Table 3. Number of hours per week of academic work by gender of full-time academic staff.

\begin{tabular}{cccccccccc}
\hline Gender & Mean & Sd & IQR & $\mathbf{0 \%}$ & $\mathbf{2 5 \%}$ & $\mathbf{5 0 \%}$ & $\mathbf{7 5 \%}$ & $\mathbf{1 0 0 \%}$ & Count \\
\hline Female & 50.75 & 15.65 & 19 & 14 & 40 & 48 & 59 & 122 & 292 \\
Male & 47.31 & 14.73 & 17 & 13.5 & 38 & 45 & 55 & 106 & 288 \\
Global & 49.04 & 15.2 & 17 & 13.5 & 40 & 47 & 57 & 122 & 580 \\
\hline
\end{tabular}

Table 4 shows the distribution of workload by gender and age for full-time staff. For the range of 65 to 70 years, the average hours per week of academic work is clearly higher in men in the sample, although the sample size for this age range is very small. However, the average hours per week of academic work is higher for women in the range from 24 to 35 years and from 45 to 65 years. In the range from 35 to 45 years, the average hours per week of academic work are nearly identical in both genders. Note that the range from 35 to 45 years coincides with the maternity and parenting period, since the most common age for women to become mothers in Spain is at 34 years (https:/ /www.ine.es/jaxi/ Datos.htm?path=/t20/e301/provi/10 / \&file=01001.px\#!tabs-tabla (accessed on 24 June 2021)). In fact, there are more mothers who have children at the age of 40 than at 25 in Spain. After the parenting period, women from 50 to 65 years work on average more than men in the same age range, nearly one day more per week.

Table 4. Hours per week of academic work by gender and age for full-time staff.

\begin{tabular}{cccccccccc}
\hline Gender.Age & Mean & Sd & IQR & $\mathbf{0 \%}$ & $\mathbf{2 5 \%}$ & $\mathbf{5 0} \%$ & $\mathbf{7 5 \%}$ & $\mathbf{1 0 0 \%}$ & Count \\
\hline Male.24-30 & 47.83 & 12.33 & 15 & 30 & 40 & 44 & 55 & 71 & 9 \\
Female.24-30 & 51.06 & 15.06 & 17 & 27 & 40.75 & 46.75 & 57.75 & 86 & 18 \\
Male.30-35 & 49.03 & 17.73 & 17.38 & 28 & 37.88 & 45.00 & 55.25 & 88 & 16 \\
Female.30-35 & 51.21 & 13.89 & 18.25 & 36 & 40 & 49 & 58.25 & 85 & 14 \\
Male.35-40 & 50.06 & 19.24 & 25.00 & 19 & 37 & 51 & 62.00 & 94.5 & 25 \\
Female.35-40 & 54.15 & 16.53 & 22 & 25 & 42.5 & 52 & 64.5 & 105 & 27 \\
Male.40-45 & 50.2 & 18.47 & 19 & 23 & 38 & 47 & 57 & 98 & 41 \\
Female.40-45 & 49.26 & 12.79 & 17.1 & 23 & 40.62 & 48 & 57.75 & 95 & 46 \\
Male.45-50 & 47.83 & 12.82 & 14 & 19 & 40.5 & 48 & 54.5 & 86 & 59 \\
Female.45-50 & 48.83 & 15.63 & 18 & 14 & 40 & 48 & 58 & 107 & 49 \\
Male.50-55 & 44.78 & 12.91 & 15.5 & 19.5 & 37 & 43 & 52.5 & 106 & 73 \\
Female.50-55 & 51.75 & 17.23 & 15.75 & 23 & 41.25 & 49.5 & 57 & 122 & 66 \\
Male.55-60 & 46.56 & 14.01 & 13.5 & 13.5 & 40 & 45 & 53.5 & 78 & 35 \\
Female.55-60 & 51.95 & 17.39 & 19.75 & 21 & 41 & 47 & 60.75 & 104.0 & 51 \\
Male.60-65 & 45.03 & 12.11 & 12.75 & 19 & 40 & 44 & 52.75 & 65 & 24 \\
Female.60-65 & 50.67 & 13.96 & 18.5 & 35 & 40 & 48.5 & 58.5 & 85 & 14 \\
Male.65-70 & 50.25 & 14.30 & 11.12 & 36 & 40.75 & 49.5 & 51.87 & 76.0 & 6 \\
Female.65-70 & 41.18 & 8.1 & 11.88 & 31 & 35.13 & 40 & 47 & 53 & 7 \\
\hline
\end{tabular}


Table 5 shows the distribution of workload by gender and category. The staff category with the smallest mean workload is AS, since it is a part-time job. For AS, the mean number of hours per week of academic work is $29.96 \mathrm{~h}$, approaching the $37.5 \mathrm{~h}$ stipulated for full-time staff. This indicates that overall AS personnel dedicate a lot of time to work, since they should have another job outside the university. If this other work is a full-time job of $37.5 \mathrm{~h}$ per week, the total time devoted to working would be $37.5+29.96=67.5 \mathrm{~h}$ per week. The categories with the next lowest mean workload are the temporary figures of doctors with no clear expectations of remaining at those universities: VI with 36.5 and POST with 41.2 mean hours per week, respectively. The next figures are TEU and TU personnel. However, the mean male workload in TEU (42) and TU (46) is lower than for females (47 and 49, respectively). The same pattern is found in CD: the mean male workload is 49 , while it is 52 for females. The staff categories with the highest mean workload are AY (64), SU (53), CU (53), AYD (52), and PRE (51). It is to be expected that AY and AYD staff work many hours, since they are temporary figures and have to gain recognition to achieve promotion within the university. This is also the case with PRE who are working on their thesis. However, the mean workload of CU is higher than for AYD and PRE, although there is a difference in mean workload between male CU (48) and female CU (55). Note also the high mean workload of SU.

Table 5. Hours per week of academic work by gender and category.

\begin{tabular}{cccccccccc}
\hline Gender.Category & Mean & Sd & IQR & $\mathbf{0 \%}$ & $\mathbf{2 5 \%}$ & $\mathbf{5 0} \%$ & $\mathbf{7 5 \%}$ & $\mathbf{1 0 0 \%}$ & Count \\
\hline Male.AY & 86.00 & NA & 0.00 & 86.0 & 86.00 & 86.0 & 86.00 & 86.0 & 1 \\
Female.AY & 53.00 & 22.63 & 16.00 & 37.0 & 45.00 & 53.0 & 61.00 & 69.0 & 2 \\
Male.AYD & 49.29 & 20.64 & 21.75 & 19.0 & 35.00 & 50.75 & 56.75 & 98.0 & 24 \\
Female.AYD & 52.80 & 18.28 & 18.75 & 23.0 & 43.00 & 50.0 & 61.75 & 122.0 & 47 \\
Male.PRE & 52.72 & 16.82 & 13.00 & 37.5 & 42.00 & 44.0 & 55.00 & 88.0 & 9 \\
Female.PRE & 50.13 & 12.32 & 16.00 & 27.0 & 42.50 & 47.0 & 58.50 & 72.0 & 15 \\
Male.CU & 48.36 & 13.27 & 18.00 & 19.0 & 40.00 & 50.0 & 58.00 & 78.0 & 52 \\
Female.CU & 54.80 & 18.91 & 23.50 & 27.0 & 41.50 & 51.0 & 65.00 & 104.0 & 29 \\
Male.CD & 49.22 & 17.48 & 18.00 & 19.0 & 38.00 & 48.0 & 56.00 & 93.0 & 40 \\
Female.CD & 52.01 & 15.29 & 18.75 & 22.0 & 40.75 & 51.0 & 59.50 & 107.0 & 55 \\
Male.POST & 44.00 & 7.36 & 6.50 & 39.5 & 39.75 & 40.0 & 46.25 & 52.5 & 3 \\
Female.POST & 37.00 & 7.07 & 5.00 & 32.0 & 34.50 & 37.0 & 39.50 & 42.0 & 2 \\
Male.AS & 27.23 & 15.20 & 21.50 & 4.0 & 14.25 & 23.0 & 35.75 & 70.0 & 59 \\
Female.AS & 32.48 & 15.16 & 22.50 & 11.0 & 19.75 & 30.5 & 42.25 & 84.0 & 64 \\
Male.TU & 45.65 & 12.70 & 11.00 & 13.5 & 40.00 & 44.0 & 51.00 & 106.0 & 141 \\
Female.TU & 48.58 & 13.10 & 16.25 & 21.0 & 39.75 & 47.0 & 56.00 & 85.0 & 119 \\
Male.SU & 52.75 & 21.10 & 32.35 & 28.0 & 34.15 & 56.0 & 66.50 & 84.0 & 7 \\
Female.SU & 52.40 & 22.10 & 26.75 & 14.0 & 37.50 & 50.0 & 64.25 & 86.0 & 11 \\
Male.TEU & 41.85 & 8.68 & 9.00 & 28.0 & 37.00 & 44.0 & 46.00 & 55.0 & 7 \\
Female.TEU & 47.31 & 16.34 & 13.00 & 17.5 & 40.50 & 47.0 & 53.50 & 83.0 & 11 \\
Male.VI & 36.50 & 8.78 & 8.25 & 30.0 & 31.50 & 33.0 & 39.75 & 46.5 & 3 \\
\hline
\end{tabular}

We detected in Table 3 that women work on average more than men in our sample. Let us analyze time distribution activity by activity for full-time staff. The results are shown in Table 6. The last two questions that appear in Table 6, are not activities but the ECTS credits assigned or reduced for management tasks. The average number of teaching hours is similar by gender, as is the number of ECTS credits assigned and reduced. However, the average hours per week devoted to student supervision, tutoring, administrative tasks, post-class tasks and preparing classes are higher for women, especially for the last two tasks. This could be the reason why female staff obtain better teaching results than their male counterparts [37]. Nevertheless, the criteria of the Spanish system for promotion in regard to teaching are mainly based on the number of teaching hours, while the quality of teaching is largely ignored [11]. Our results show that the current criteria could be revised 
to take into account the tasks carried out by women. On the other hand, the average hours per week devoted to research and transfer tasks is higher for men, although not so much. The difference is greater for pre- and post-class tasks. Remember that these differences are on a weekly scale, so the differences are amplified when we consider the whole year.

Table 6. Hours per week of each academic activity by gender for full-time staff. Q.number indicates the number of the question in the survey.

\begin{tabular}{|c|c|c|c|c|c|c|c|c|c|}
\hline Gender & Mean & Sd & IQR & $0 \%$ & $25 \%$ & $50 \%$ & $75 \%$ & $100 \%$ & Count \\
\hline \multicolumn{10}{|c|}{ Teaching hours (Q.1) } \\
\hline Male & 7.15 & 3.07 & 3 & 0 & 5 & 7 & 8 & 20 & 288 \\
\hline Female & 7.26 & 3.19 & 4 & 2 & 5 & 7 & 9 & 20 & 292 \\
\hline \multicolumn{10}{|c|}{ Tutoring (Q.2) } \\
\hline Male & 4.25 & 3.36 & 4 & 0 & 2 & 4 & 6 & 20 & 288 \\
\hline Female & 4.75 & 3.11 & 4 & 0 & 2 & 4 & 6 & 20 & 292 \\
\hline \multicolumn{10}{|c|}{ Preparing classes (Q.3) } \\
\hline Male & 7.33 & 5.23 & 6 & 0.0 & 4 & 6 & 10 & 35 & 288 \\
\hline Female & 8.96 & 5.72 & 8 & 0.5 & 4 & 8 & 12 & 30 & 292 \\
\hline \multicolumn{10}{|c|}{ Post-class (Q.4) } \\
\hline Male & 3.92 & 2.98 & 3 & 0 & 2 & 3 & 5 & 20 & 288 \\
\hline Female & 5.31 & 4.37 & 3 & 0 & 3 & 4 & 6 & 25 & 292 \\
\hline \multicolumn{10}{|c|}{ Student supervision (Q.5) } \\
\hline Male & 4.03 & 3.83 & 3 & 0 & 2 & 3 & 5 & 20 & 288 \\
\hline Female & 4.41 & 4.38 & 4 & 0 & 2 & 3 & 6 & 40 & 292 \\
\hline \multicolumn{10}{|c|}{ Administrative tasks (Q.6) } \\
\hline Male & 4.31 & 6.56 & 5 & 0 & 0 & 2 & 5 & 40 & 288 \\
\hline Female & 4.74 & 6.06 & 8 & 0 & 0 & 2 & 8 & 30 & 292 \\
\hline \multicolumn{10}{|c|}{ Research (Q.7) } \\
\hline Male & 13.34 & 9.52 & 14 & 0 & 6 & 10.5 & 20 & 60 & 288 \\
\hline Female & 12.78 & 9.59 & 15 & 0 & 5 & 10.0 & 20 & 50 & 292 \\
\hline \multicolumn{10}{|c|}{ Transfer tasks (Q.8) } \\
\hline Male & 2.96 & 4.79 & 4 & 0 & 0 & 2 & 4 & 50 & 288 \\
\hline Female & 2.53 & 3.36 & 4 & 0 & 0 & 2 & 4 & 20 & 292 \\
\hline \multicolumn{10}{|c|}{ ECTS credits assigned (Q.12) } \\
\hline Male & 18.93 & 6.8 & 9 & 0 & 15 & 20 & 24 & 36 & 288 \\
\hline Female & 19.07 & 7.48 & 9 & 0 & 15 & 21 & 24 & 32 & 292 \\
\hline \multicolumn{10}{|c|}{ ECTS credits reduced by management position (Q.13) } \\
\hline Male & 2.25 & 4.04 & 3 & 0 & 0 & 0 & 3 & 23 & 288 \\
\hline Female & 2.26 & 4.03 & 3.2 & 0 & 0 & 0 & 3.2 & 23 & 292 \\
\hline
\end{tabular}

Knowing the teaching workload is very important, since staff are assigned a certain number of ECTS credits each year. If we add up all the teaching-related tasks, we observe that the female staff in our sample dedicate on average $29.77 \mathrm{~h}$ per week and the male staff $25.66 \mathrm{~h}$ per week (a difference of $4.11 \mathrm{~h}$ per week). Remember that the legal working week consists of $37.5 \mathrm{~h} /$ week, so, if teaching duties imply so many hours, there are not many hours left for research, transfer, and administrative tasks. 
It is accepted that one ECTS credit represents approximately 25 to $30 \mathrm{~h}$ per year of student workload, but how much does one ECTS credit represent for teachers? We can broadly estimate this as follows. Teaching takes place within 30 weeks per academic year, although this is an underestimation since there are also teaching duties during the exam periods. Therefore, we can (under)estimate the total number of teaching hour per course as $29.77 \times 30=893.1$ for female staff and $25.66 \times 30=769.8 \mathrm{~h}$ for male staff. Then, we divide this quantity by 19 ECTS credits assigned on average. This means that 1 ECTS credit represents an average of $47.0 \mathrm{~h} /$ year for female staff and $40.5 \mathrm{~h}$ /year for male staff, i.e., approximately $43.8 \mathrm{~h} /$ year.

Nevertheless, the assigned ECTS credits depend mainly on the staff category. These are summarized in Table 7. TEU is the staff category with the highest average number of ECTS credits assigned, while the second highest category is AYD. However, TEU staff do not have research duties, so AYD is the highest category with research duties. Although AYD is the natural beginner category in the Spanish university, it has the highest number of credits assigned on average in our sample. In other countries, such as France, beginners have fewer teaching responsibilities at first, which is quite sensible, instead of burdening beginners with teaching when they must also gain recognition for research to achieve promotion.

Table 7. Number of ECTS credits assigned per staff category.

\begin{tabular}{cccccccccc}
\hline Category & Mean & Sd & IQR & $\mathbf{0 \%}$ & $\mathbf{2 5 \%}$ & $\mathbf{5 0 \%}$ & $\mathbf{7 5 \%}$ & $\mathbf{1 0 0 \%}$ & Count \\
\hline AY & 6.3 & 0.57 & 0.5 & 6.0 & 6.0 & 6 & 6.5 & 7.0 & 3 \\
AYD & 21.39 & 4.03 & 2.5 & 6.0 & 21.5 & 22 & 24.0 & 25.5 & 71 \\
PRE & 5.75 & 1.13 & 0.0 & 3.0 & 6.0 & 6 & 6.0 & 8.0 & 24 \\
CU & 16.36 & 5.56 & 7.00 & 4.5 & 13.0 & 16 & 20.0 & 28.0 & 81 \\
CD & 20.56 & 6.88 & 6.00 & 0.0 & 18.0 & 24 & 24.0 & 32.0 & 95 \\
Other (not specified) & 7.00 & 1.41 & 1.0 & 6.0 & 6.5 & 7 & 7.5 & 8.0 & 2 \\
POST & 6.80 & 5.71 & 5.0 & 0.0 & 3.0 & 8 & 8.0 & 15.0 & 5 \\
AS & 11.87 & 5.91 & 12.0 & 0.0 & 6.0 & 12 & 18.0 & 32.0 & 123 \\
TU & 19.95 & 6.78 & 8.0 & 5.0 & 16.0 & 20 & 24.0 & 35.0 & 260 \\
SU & 18.11 & 7.61 & 13.5 & 6.0 & 10.5 & 19 & 24.0 & 30.0 & 18 \\
TEU & 25.05 & 5.93 & 7.2 & 14.0 & 22.5 & 24 & 29.7 & 36.0 & 18 \\
VI & 16.66 & 4.16 & 4.0 & 12.0 & 15.0 & 18 & 19.0 & 20.0
\end{tabular}

We have also analyzed the age by staff category. The results are shown in Table 8 . In all the stable (AY, AYD, CU, CD, TU, TEU) categories, the average age for females is higher than for male staff, so it seems that female staff enter later and/or remain for longer in different stable categories before being promoted to the next category in the system. It is also significant that 39 years is the average age for AYD, the beginners in the Spanish university system. Therefore, people are entering the university when they are not so young, and these people, at almost 40 years old, do not have a permanent position. Remember that AYD is a temporary staff category. 
Table 8. Age by staff category and gender.

\begin{tabular}{cccccccccc}
\hline Category & Mean & Sd & IQR & $\mathbf{0 \%}$ & $\mathbf{2 5 \%}$ & $\mathbf{5 0 \%}$ & $\mathbf{7 5 \%}$ & $\mathbf{1 0 0 \%}$ & Count \\
\hline Male.AY & 34.00 & - & 0.00 & 34 & 34.00 & 34.0 & 34.00 & 34 & 1 \\
Female.AY & 37.00 & 2.82 & 2.00 & 35 & 36.00 & 37.0 & 38.00 & 39 & 2 \\
Male.AYD & 37.79 & 4.82 & 5.50 & 31 & 34.75 & 37.5 & 40.25 & 51 & 24 \\
Female.AYD & 39.81 & 6.75 & 8.00 & 29 & 35.00 & 40.0 & 43.00 & 60 & 47 \\
Male.PRE & 27.77 & 2.68 & 2.00 & 24 & 26.00 & 27.0 & 28.00 & 32 & 9 \\
Female.PRE & 27.86 & 6.22 & 1.50 & 24 & 25.00 & 26.0 & 26.50 & 48 & 15 \\
Male.CU & 55.51 & 5.89 & 9.00 & 41 & 52.00 & 55.0 & 61.00 & 66 & 52 \\
Female.CU & 56.48 & 5.29 & 5.00 & 50 & 53.00 & 56.0 & 58.00 & 69 & 29 \\
Male.CD & 44.50 & 6.69 & 7.25 & 33 & 40.00 & 43.0 & 47.25 & 67 & 40 \\
Female.CD & 45.80 & 5.87 & 9.00 & 34 & 41.00 & 46.0 & 50.00 & 59 & 55 \\
Male.POST & 32.33 & 1.52 & 1.50 & 31 & 31.50 & 32.0 & 33.00 & 34 & 3 \\
Female.POST & 38.00 & 2.82 & 2.00 & 36 & 37.00 & 38.0 & 39.00 & 40 & 2 \\
Male.AS & 45.76 & 10.58 & 15.50 & 24 & 40.00 & 45.0 & 55.50 & 65 & 59 \\
Female.AS & 43.29 & 9.64 & 13.50 & 24 & 36.75 & 43.5 & 50.25 & 62 & 64 \\
Male.TU & 50.82 & 6.26 & 7.00 & 35 & 47.00 & 50.0 & 54.00 & 66 & 141 \\
Female.TU & 52.01 & 6.33 & 8.00 & 34 & 48.00 & 52.0 & 56.00 & 67 & 119 \\
Male.SU & 37.71 & 5.99 & 6.50 & 29 & 34.50 & 39.0 & 41.00 & 45
\end{tabular}

Let us now analyze the questions related to care, domestic chores and leisure time. Table 9 displays the results. The average hours per week devoted to caring for people is $6.5 \mathrm{~h}$ higher for female staff than for male staff in our sample. If we focus on the $25 \%$ of people who devoted the most hours to care, the difference increases up to $12.25 \mathrm{~h}$ per week. The weekly average spent on domestic chores is also higher for women than for men $(3 \mathrm{~h}$ per week). On the contrary, the weekly average for leisure activities is higher for men than for women $(2.3 \mathrm{~h})$. Table 10 shows the summarized statistics for care of people according to age and gender. The highest average is attained for female staff between 35 and 40 years, which coincides with maternity and parenting. In this case, the difference between women and men is $30 \mathrm{~h}$ per week. This gap continues in the following age ranges, although it is not so large. The distribution of this variable is very skewed, since $32 \%$ of the sample do not devote any time to caring for other people. Therefore, for this variable, it is better to look for the median. The difference between the median of women and men is $30 \mathrm{~h} /$ week for 35-40 years, $11 \mathrm{~h}$ /week for 40-45 years, $9 \mathrm{~h}$ /week for $45-50$ and 50-55 years, and around $5 \mathrm{~h} /$ week for the following age ranges. For ages below 35 years, the median is zero for both genders. It could be surprising that the average time devoted to care time for men aged 30-35 years is higher than for women of the same age range, but this is misleading. Six of the 24 men of this age have children, in fact, 4 have two children, but only 2 women of this age have one child. 
Table 9. Hours per week of activities outside the university by gender. Q.number indicates the number of the question in the survey.

\begin{tabular}{|c|c|c|c|c|c|c|c|c|c|}
\hline Gender & Mean & Sd & IQR & $0 \%$ & $25 \%$ & $50 \%$ & $75 \%$ & $100 \%$ & Count \\
\hline \multicolumn{10}{|c|}{ Caring for people (Q.9) } \\
\hline Male & 8.95 & 12.89 & 11 & 0 & 0 & 3 & 11 & 60 & 347 \\
\hline Female & 15.45 & 16.67 & 22.25 & 0 & 1 & 10 & 23.25 & 80 & 356 \\
\hline \multicolumn{10}{|c|}{ Leisure and personal entertainment (Q.10) } \\
\hline Male & 12.50 & 8.3 & 10 & 0 & 6 & 10 & 16 & 42 & 347 \\
\hline Female & 10.19 & 7.29 & 9 & 0 & 5 & 10 & 14 & 40 & 356 \\
\hline \multicolumn{10}{|c|}{ Domestic chores (Q.11) } \\
\hline Male & 9.48 & 6.20 & 7 & 0 & 5 & 8 & 12 & 30 & 347 \\
\hline Female & 12.51 & 7.34 & 9 & 0 & 7 & 10 & 16 & 40 & 356 \\
\hline
\end{tabular}

Table 10. Number of hours per week of people-care by gender and age.

\begin{tabular}{cccccccccc}
\hline Gender.Age & Mean & Sd & IQR & $\mathbf{0 \%}$ & $\mathbf{2 5 \%}$ & $\mathbf{5 0} \%$ & $\mathbf{7 5 \%}$ & $\mathbf{1 0 0} \%$ & Count \\
\hline Male.24-30 & 1.75 & 4.11 & 1.00 & 0 & 0.0 & 0.0 & 1.00 & 14 & 12 \\
Female.24-30 & 2.26 & 3.41 & 4.00 & 0 & 0.0 & 0.0 & 4.00 & 10 & 23 \\
Male.30-35 & 11.83 & 20.81 & 10.50 & 0 & 0.0 & 0.0 & 10.50 & 60 & 24 \\
Female.30-35 & 3.95 & 6.54 & 6.50 & 0 & 0.0 & 0.0 & 6.50 & 20 & 22 \\
Male.35-40 & 4.21 & 8.07 & 5.25 & 0 & 0.0 & 0.0 & 5.25 & 40 & 28 \\
Female.35-40 & 34.22 & 28.62 & 40.50 & 0 & 9.5 & 30.0 & 50.00 & 100 & 40 \\
Male.40-45 & 15.03 & 14.67 & 24.00 & 0 & 1.0 & 10.0 & 25.00 & 60 & 56 \\
Female.40-45 & 23.16 & 19.33 & 34.50 & 0 & 3.0 & 21 & 37.50 & 64 & 55 \\
Male.45-50 & 12.50 & 15.83 & 20.00 & 0 & 0.0 & 6.0 & 20.00 & 60 & 66 \\
Female.45-50 & 17.64 & 15.92 & 22.25 & 0 & 4.0 & 15.0 & 26.25 & 50 & 60 \\
Male.50-55 & 8.04 & 8.97 & 10.50 & 0 & 0.0 & 5.0 & 10.50 & 40 & 80 \\
Female.50-55 & 16.26 & 16.40 & 15.00 & 0 & 5.0 & 14.0 & 20.00 & 100 & 75 \\
Male.55-60 & 7.53 & 12.43 & 7.00 & 0 & 0.0 & 0.0 & 7.00 & 45 & 45 \\
Female.55-60 & 9.00 & 10.98 & 15.00 & 0 & 0.0 & 5.0 & 15.00 & 52 & 57 \\
Male.60-65 & 2.10 & 2.74 & 4.00 & 0 & 0.0 & 0.0 & 4.00 & 10 & 29 \\
Female.60-65 & 7.47 & 6.19 & 7.00 & 0 & 3.0 & 6.0 & 10.00 & 20 & 17 \\
Male.65-70 & 0.57 & 0.97 & 1.00 & 0 & 0.0 & 0.0 & 1.00 & 2 & 7 \\
Female.65-70 & 8.85 & 10.83 & 11.50 & 0 & 1.0 & 5.0 & 12.50 & 30 & 7 \\
\hline
\end{tabular}

\section{Unsupervised Learning}

Until now, we have limited ourselves to describing each variable disaggregated by different factors. However, for having a more complete picture of the profiles in the Spanish university staff, we can carry out a multivariate analysis taking into account all the variables jointly. Therefore, we apply several unsupervised statistical learning techniques in this section.

Firstly, a cluster analysis is applied, in particular the classical $k$-means [38] (Ch. 14). This analysis allows us to segment the data and see which groups are present in the data. We consider four features or blocks for carrying out the analysis. These blocks are built from the original variables, according to the type of activity performed, and are the following ones: Teaching is Block 1 and includes the questions from 1 to 5; Block 2: Research and transfer, with questions 7 and 8; Block 3: Management (question 6); Block 4: Care and home (questions 9 and 11). Then, each block is standardized (the mean is subtracted and the results are divided by the standard deviation), in order that the blocks have the same weight. When data is standardized the mean corresponds to the zero value, and if the distribution is Normal, $95 \%$ of the values are between -2 to 2 . 
In order to determine the number of clusters, we use the elbow or kink criterion [38] (Ch. 14), and five clusters are selected.

$k$-means returns the centroids of each group. Table 11 shows the standardized values of the centroids, which can be as the representantive point of each cluster. It is also returns the membership of each point to a unique cluster. The column 'Count' contains the number of subjects assigned automatically by $k$-means to each cluster.

Table 11. Cluster centrois for each block.

\begin{tabular}{cccccc}
\hline Cluster & Teaching & Research & Management & Care & Count \\
\hline 1 & -0.25 & -0.6 & -0.32 & -0.51 & 247 \\
2 & 1.70 & -0.23 & -0.05 & 0.04 & 99 \\
3 & -0.14 & -0.15 & 2.33 & 0.08 & 74 \\
4 & -0.37 & 1.18 & -0.34 & -0.39 & 177 \\
5 & -0.30 & -0.25 & -0.25 & 1.74 & 106 \\
\hline
\end{tabular}

We notice that cluster number 1, which is the most numerous, has low scores in all the blocks, i.e., it represents an academic that works less than the mean in Teaching, Research, Management and Care, especially in Research and Care. The other clusters also have low or medium scores in all the blocks, except in one of them, i.e., it highlights in one of the blocks. The block with high scores in groups 2 to 5 is different. The centroid of cluster 2 represents an academic with medium values in Research, Management and Care, but with a high workload in Teaching. The centroid 3 represents an academic with mean values in all the blocks, except in Management, where her/his workload is high. The centroid 4 represents an academic with medium-low values in all the blocks, except in Research, with high workload in this area. Finally, centroid 5 represents an academic with medium values in all blocks, except in Care, where he/she devotes quite a bit more time than the mean.

Table 12 includes the mean values for the members of each group for different variables. As before, $Q$ indicates the question of the survey. Note that the mean number of children in cluster 5, which focuses on care, is 1.87 , which is the highest of all the groups. Cluster 4 , which focuses on Research, has the highest mean in leisure time and the lowest in care, and the lowest teaching duties (Q1). These teaching duties are more or less similar to the individuals in cluster 3 , which is centered on administrative tasks. The highest teaching duties are for individuals in group 2; moreover, they devoted a lot of time to preparing classes. Nevertheless, this group also has a high average in Research, so its total academic workload is very high, nearly $63 \mathrm{~h} /$ week, the highest academic workload of all the groups. Cluster 3 has the second highest academic workload, with $56 \mathrm{~h} /$ week. The third highest academic workload corresponds with cluster 4, with $52 \mathrm{~h} /$ week. Academic workload for group 5 is $38 \mathrm{~h} /$ week, while, for group 1, it is $34 \mathrm{~h} /$ week. Staff in group 1 is who devotes less hours to domestic work. Group 1 is the most numerous, and it represents $38 \%$ of the sample. Note that having an average academic workload of $34 \mathrm{~h} /$ week does not imply that they are not fulfilling their obligations of working $37.5 \mathrm{~h} /$ week, since we are also considering part-time staff, such as AS, which are a very numerous category, and they should not work $37.5 \mathrm{~h} /$ week at university, therefore decreasing the average. 
Table 12. Average values of weekly workload in hours for individuals of each cluster.

\begin{tabular}{|c|c|c|c|c|c|c|}
\hline Cluster & No. Children & Q1 (Teaching hours) & Q2 (Tutoring) & Q3 (Preparing classes) & Q4 (Post-class) & Q5 (Supervision \\
\hline 1 & 1.09 & 7.17 & 4.17 & 6.58 & 3.86 & 2.99 \\
\hline 2 & 1.23 & 9.33 & 7.42 & 15.43 & 9.30 & 6.34 \\
\hline 3 & 1.38 & 6.02 & 4.38 & 7.10 & 4.48 & 4.18 \\
\hline 4 & 1.07 & 6.13 & 3.28 & 6.73 & 3.49 & 3.81 \\
\hline 5 & 1.87 & 7.04 & 3.87 & 6.26 & 3.59 & 3.44 \\
\hline Cluster & Q6 (Administration) & Q7 (Research) & Q8 (Transfer tasks) & Q9 (Care) & Q10 (Leisure) & Q11 (Domestic) \\
\hline 1 & 1.87 & 6.17 & 1.44 & 5.16 & 11.17 & 8.79 \\
\hline 2 & 3.48 & 9.66 & 2.01 & 12.28 & 9.70 & 11.74 \\
\hline 3 & 17.73 & 9.82 & 2.70 & 13.18 & 11.54 & 11.57 \\
\hline 4 & 1.77 & 22.47 & 4.54 & 5.75 & 13.67 & 10.40 \\
\hline 5 & 2.31 & 9.65 & 1.76 & 38.92 & 9.18 & 16.18 \\
\hline
\end{tabular}

Table 13 shows the distribution by gender in the different clusters. The first and fourth groups mainly constituted men, whereas groups 2,3 , and, especially, 5 , constituted mostly women. Remember that group 5 is focused on care. Cluster 1 was the group with lowest workload, and cluster 2 was the group with highest workload. Group 3 for management tasks and group 4 focused on research are more equally distributed between genders.

Table 13. Distribution by gender in the different clusters (percentage between parenthesis).

\begin{tabular}{cccccc}
\hline Cluster & $\mathbf{1}$ & $\mathbf{2}$ & $\mathbf{3}$ & $\mathbf{4}$ & $\mathbf{5}$ \\
\hline Men & $149(60.3 \%)$ & $33(33.3 \%)$ & $35(47.3 \%)$ & $95(53.7 \%)$ & $35(33 \%)$ \\
Women & $98(39.7 \%)$ & $66(66.7 \%)$ & $39(52.7 \%)$ & $82(46.3 \%)$ & $71(67 \%)$ \\
\hline
\end{tabular}

Table 14 shows the distribution in the different clusters according to labor category and gender. Let us discuss the results for the main categories. For AYD, group 2 is the majority for women and group 1 for men. The rest of individuals are divided between group 2 and 4 for men, but group 1, 4, and 5 for women. As they are beginners, the percentage of group 3, for management tasks is low, although is higher for men. PRE are mostly in group 4, devoted to research. The profiles in CU for men and women are different. In both cases, group 4 is the majority. However, in $\mathrm{CU}$ men, group 1 is very important. In CU women, group 5 , and also group 3 , is higher, i.e., again, caring is also more present in $\mathrm{CU}$ women, and $\mathrm{CU}$ women are more involved in management tasks than CU men. In CD, the majority group is 1 , but with very different percentages between men and women. In $\mathrm{TU}$, the majority group is 1 for men, but not for women. For $\mathrm{CD}$ and $\mathrm{TU}$ men, it is above $40 \%$, but for women it is below $26 \%$. An important part of TU and CD women belong to group 5, and also to group 2, more than TU and CD men. For group 3, the membership is similar between CD and TU men and women, but it is a bit higher for women. For CD and TU men, the membership to group 4 is a bit higher than for women. In the case of AS, the membership in group 1 is the highest, especially in AS men. It is also the case with TEU, although, in this case, it is higher for TEU women. In regard to SU, the highest membership in SU men is in group 1, but, in group 2, it is SU women. 
Table 14. Percentage distribution in cluster by gender and labor category.

\begin{tabular}{ccccccc}
\hline Gender.Category & 1 & $\mathbf{2}$ & $\mathbf{3}$ & $\mathbf{4}$ & $\mathbf{5}$ & Count \\
\hline Male.AY & 0.0 & 0.0 & 0.0 & 100.0 & 0.0 & 1 \\
Female.AY & 50.0 & 50.0 & 0.0 & 0.0 & 0.0 & 2 \\
Male.AYD & 37.5 & 29.2 & 8.3 & 16.7 & 8.3 & 24 \\
Female.AYD & 25.5 & 27.7 & 2.1 & 23.4 & 21.3 & 47 \\
Male.PRE & 22.2 & 0.0 & 0.0 & 77.8 & 0.0 & 9 \\
Female.PRE & 6.7 & 6.7 & 0.0 & 86.7 & 0.0 & 15 \\
Male.CU & 32.7 & 5.8 & 13.5 & 46.2 & 1.9 & 52 \\
Female.CU & 17.2 & 13.8 & 17.2 & 41.4 & 10.3 & 29 \\
Male.CD & 40.0 & 10.0 & 17.5 & 22.5 & 10.0 & 40 \\
Female.CD & 25.5 & 18.2 & 20.0 & 18.2 & 18.2 & 55 \\
Male.POST & 0.0 & 0.0 & 0.0 & 100.0 & 0.0 & 3 \\
Female.POST & 0.0 & 0.0 & 0.0 & 0.0 & 100.0 & 2 \\
Male.AS & 66.1 & 6.8 & 0.0 & 8.5 & 18.6 & 59 \\
Female.AS & 53.1 & 7.8 & 0.0 & 10.9 & 28.1 & 64 \\
Male.TU & 41.8 & 8.5 & 12.1 & 28.4 & 9.2 & 141 \\
Female.TU & 19.3 & 20.2 & 16.8 & 21.8 & 21.8 & 119 \\
Male.SU & 42.9 & 28.6 & 14.3 & 14.3 & 0.0 & 7 \\
Female.SU & 18.2 & 45.5 & 0.0 & 18.2 & 18.2 & 11 \\
Male.TEU & 42.9 & 14.3 & 14.3 & 0.0 & 28.6 & 7 \\
Female.TEU & 54.5 & 27.3 & 18.2 & 0.0 & 0.0 & 11 \\
Male.VI & 33.3 & 0.0 & 0.0 & 33.3 & 33.3 & 3 \\
\hline
\end{tabular}

Besides cluster analysis, we have also applied archetype analysis and self-organizing maps (SOM) obtaining similar results.

\section{Conclusions}

We have analyzed the workload of 703 Spanish academic staff. As novelty, we have used data science tools. We have used five number summary, besides the classical statistical summaries, which are more appropriate for skewed distributions. Furthermore, we have applied unsupervised multivariate statistical learning techniques, such as cluster analysis.

We have commented the limitations, which are mainly due to the selection of the sample, but this study has allowed us to the detect problems and patterns. The exact extent of them can be further determined with random samples in future research. The survey does not examine subjective processes that take place within academic departments, such as access to informal support networks, mentorship, etc., but it focus on measuring the workload in different activities during the period of classes. In future work, activities during the period of exams can be also measured.

The findings can be useful for policy-making, especially now that there are planned legal modifications in the Spanish university environment. Note that workload allocations have an impact on academic satisfaction and working life [39], especially for women [40].

Some of the most important findings are the followings. Eighty percent of the academic staff in the sample works more than $37.5 \mathrm{~h}$. Fifty percent of the sample works more than $47 \mathrm{~h}$, i.e., more than one day extra work per week.This could suggest that staff can be overloaded. In regard to gender, women work more hours per week on average than men. The labor figures with highest mean workload are AY, AYD, SU, CU, and PRE. Although AYD is the natural beginner figure in the Spanish university, it has the highest number of credits assigned on average in our sample for labor figures with research duties. This could suggest that resources are not allocated correctly, since beginners should not be burdened with teaching. Moreover, 39 years is the average age for AYD, so the beginners in the Spanish university system are not too young. This could be a signal of a problem in the Spanish university system. 
Although the teaching duties (ECTS credits assigned) for women and men in our sample are nearly identical on average, women dedicate on average more time to tutoring, preparing classes, post-class tasks, and student supervision, which we could consider as improving the teaching quality. In fact, the difference is $4 \mathrm{~h} /$ week. Therefore, $1 \mathrm{ECTS}$ credit represents on average $47.0 \mathrm{~h}$ /year per female staff and $40.5 \mathrm{~h}$ /year per male staff. However, teaching quality is not nearly taking into account in the national system of evaluation for promoting.

The average weekly hours devoted to care of people and domestic work is $10 \mathrm{~h}$ per week higher for women. But, the difference is $30 \mathrm{~h}$ per week, on average, between women and men for care (without considering the domestic work) during the range from 35 to 40 years, the most frequent period of parenting. This is a clear signal that gender roles continue to be present in the academic staff.

Although we have found that on average men devote more weekly time to research, the difference is very small, $0.6 \mathrm{~h}$ per week for full-time staff. Therefore, it seems that the pattern in Spain does not coincide with that of American research universities [7].

We have found five clear workload profiles in the Spanish academic staff. One with low workload compared to the rest of staff, although its average academic workload is $34 \mathrm{~h} /$ week; one with very high workload, especially in teaching; another one with high workload in management; another one with high workload in research; and one profile with high workload in care and domestic tasks.

In summary, the legal modifications in the Spanish university environment should address the key findings: (a) the beginners in the Spanish university system, AYD, are not so young and are also loaded with teaching; (b) the majority of the academic staff works non-recognized overtime, which would be a violation of Spanish labor law; (c) there is a gender gap about the time spend on quality of teaching and caring tasks. This would be also a violation of the Spanish equality law, since co-responsibility must be fostered by all the administrations, governments, and universities, and obviously they are failing in this task.

More information can be gathered from our data in the future. As data are available, other researchers can carry out further analysis and compare their results in other countries. Other future line of research would be to analyze the possible consequence of COVID-19 pandemic in the workload of academic staff and changes in the distribution of activities. According to other approaches [41,42], the more time being spent on caregiving responsibilities during the COVID-19 pandemic has dropped female scientific productivity. Therefore, policies should also address this gendered effect [43].

Author Contributions: Conceptualization, I.C. and I.E.; data curation, I.C.; formal analysis, I.C. and I.E.; funding acquisition, I.E.; investigation, I.C. and I.E.; methodology, I.C. and I.E.; resources, I.C.; software, I.C. and I.E.; writing — original draft preparation, I.C. and I.E.; and writing—review and editing, I.C. and I.E. Both authors have read and agreed to the published version of the manuscript.

Funding: This research was funded by the Spanish Ministry of Science, Innovation and Universities (AEI/FEDER, EU) grant number DPI2017-87333-R and Universitat Jaume I grant number UJI-B2020-22.

Informed Consent Statement: Not applicable.

Data Availability Statement: The R code and data for reproducing the results can be found at http:/ / www3.uji.es/ epifanio/RESEARCH/workload.zip (accessed on 24 June 2021).

Acknowledgments: The authors would like to thank Universitat Jaume I for allowing them to send the questionnaire to its academic staff. The authors are also grateful to the academic staff that kindly completed the survey.

Conflicts of Interest: The authors declare no conflict of interest. The funders had no role in the design of the study; in the collection, analysis, or interpretation of data; in the writing of the manuscript, or in the decision to publish the results. 


\section{References}

1. Visvizi, A.; Lytras, M.D.; Sarirete, A. Emerging Technologies and Higher Education: Management and Administration in Focus. In Management and Administration of Higher Education Institutions at Times of Change; Emerald Publishing Limited: Bingley, UK, 2019; pp. 1-11.

2. Brennan, J. Higher education and social change. High. Educ. 2008, 56, 381-393. [CrossRef]

3. Pavlin, S. Should higher education institutions worry about the precarisation of professional work? Ann.-Anal. Istrske Mediter.-Stud.-Ser. Hist. Sociol. 2018, 28, 853-864.

4. Visvizi, A.; Lytras, M.; Sarirete, A. Management and Administration of Higher Education Institutions in Times of Change; Emerald Publishing Limited: Bingley, UK, 2019.

5. Flaherty, C. So Much To Do, So Little Time. Inside High. Ed. 2014. Available online: https://www.insidehighered.com/news/20 14/04/09/research-shows-professors-work-long-hours-and-spend-much-day-meetings (accessed on 24 June 2021).

6. Misra, J.; Lundquist, J.H.; Holmes, E.; Agiomavritis, S. The ivory ceiling of service work. Academe 2011, 97, 22-26.

7. O'Meara, K.; Kuvaeva, A.; Nyunt, G.; Waugaman, C.; Jackson, R. Asked More Often: Gender Differences in Faculty Workload in Research Universities and the Work Interactions That Shape Them. Am. Educ. Res. J. 2017, 54, 1154-1186. [CrossRef]

8. de Madariaga, I.S.; de la Rica, S.; Dolado, J. Libro Blanco. Situación de las Mujeres en la Ciencia Española; Ministero de Ciencia e Innovación: Madrid, Spain, 2011.

9. Schiebinger, L.; Gilmartin, S.K. Housework is an academic issue. Academe 2010, 96, 39-44.

10. Smidt, T.B.; Pétursdóttir, G.M.; Einarsdóttir, P. How do you take time? Work-life balance policies versus neoliberal, social and cultural incentive mechanisms in Icelandic higher education. Eur. Educ. Res. J. 2017, 16, 123-140. [CrossRef]

11. Epifanio, I. Lejos de la igualdad efectiva entre hombres y mujeres en el profesorado universitario. TE-Trab. De La Enseñanza CCOO Enseñanza 2019, 372, 24-27.

12. Acker, J. Hierarchies, jobs, bodies: A theory of gendered organizations. Gend. Soc. 1990, 4, 139-158. [CrossRef]

13. Acker, J. Inequality regimes: Gender, class, and race in organizations. Gend. Soc. 2006, 20, 441-464. [CrossRef]

14. Smith, D.E. Institutional Ethnography: A Sociology for People; Rowman: Oxford, UK, 2005.

15. Hanasono, L.K.; Broido, E.M.; Yacobucci, M.M.; Root, K.V.; Peña, S.; O’Neil, D.A. Secret service: Revealing gender biases in the visibility and value of faculty service. J. Divers. High. Educ. 2019, 12, 85. [CrossRef]

16. Heijstra, T.M.; Steinthorsdóttir, F.S.; Einarsdóttir, T. Academic career making and the double-edged role of academic housework. Gend. Educ. 2017, 29, 764-780. [CrossRef]

17. Heijstra, T.M.; Einarsdóttir, P.; Pétursdóttir, G.M.; Steinpórsdóttir, F.S. Testing the concept of academic housework in a European setting: Part of academic career-making or gendered barrier to the top? Eur. Educ. Res. J. 2017, 16, 200-214. [CrossRef]

18. Bird, S.R. Unsettling universities' incongruous, gendered bureaucratic structures: A case-study approach. Gender Work Organ. 2011, 18, 202-230. [CrossRef]

19. Baez, B. Race-related service and faculty of color: Conceptualizing critical agency in academe. High. Educ. 2000, 39, 363-391. [CrossRef]

20. Griffin, K.A.; Bennett, J.C.; Harris, J. Marginalizing merit? Gender differences in Black faculty D/discourses on tenure, advancement, and professional success. Rev. High. Educ. 2013, 36, 489-512. [CrossRef]

21. Stanley, C.A. Coloring the academic landscape: Faculty of color breaking the silence in predominantly White colleges and universities. Am. Educ. Res. J. 2006, 43, 701-736. [CrossRef]

22. Umbach, P.D. The contribution of faculty of color to undergraduate education. Res. High. Educ. 2006, 47, 317-345. [CrossRef]

23. Jabbaz, M.; Samper-Gras, T.; Díaz, C. La brecha salarial de género en las instituciones científicas. Estudio de caso. Convergencia 2019, 26, 1-27. [CrossRef]

24. Allen, H.L. Faculty workload and productivity: Ethnic and gender disparities. In The NEA 1997 Almanac of Higher Education; National Education Assn: Washington, DC, USA, 1997; pp. 25-42.

25. Allen, H.L. Faculty Workload and Productivity: Gender Comparisons. In The NEA 1998 Almanac of Higher Education; National Education Assn: Washington, DC, USA, 1998; pp. 29-44.

26. Rafnsdóttir, G.L.; Heijstra, T.M. Balancing Work-family Life in Academia: The Power of Time. Gender Work Organ. 2013, 20, 283-296. [CrossRef]

27. Sharafizad, F.; Brown, K.; Jogulu, U.; Omari, M. Letting a Picture Speak a Thousand Words: Arts-based Research in a Study of the Careers of Female Academics. Sociol. Methods Res. 2020. [CrossRef]

28. Secretaría General de Universidad. Datos y Cifras del Sistema Universitario Español. Publicación 2018-2019; Ministerio de Ciencia, Inovación y Universidades. 2019. Available online: https:/ / www.universidades.gob.es/ (accessed on 24 June 2021).

29. Hernández, C. El 72 El Mundo 2018. Available online: https://www.elmundo.es/comunidad-valenciana/castellon/2018/04/16 /5ad492eeca4741da5f8b4584.html (accessed on 24 June 2021).

30. Cheung, K.L.; Peter, M.; Smit, C.; de Vries, H.; Pieterse, M.E. The impact of non-response bias due to sampling in public health studies: A comparison of voluntary versus mandatory recruitment in a Dutch national survey on adolescent health. BMC Public Health 2017, 17, 1-10. [CrossRef]

31. Locke, G.R.; Schleck, C.D.; Ziegenfuss, J.Y.; Beebe, T.J.; Zinsmeister, A.R.; Talley, N.J. A low response rate does not necessarily indicate non-response bias in gastroenterology survey research: A population-based study. J. Public Health 2013, 21, 87-95.

32. Menachemi, N. Assessing response bias in a web survey at a university faculty. Eval. Res. Educ. 2011, 24, 5-15. [CrossRef] 
33. Armstrong, J.S.; Overton, T.S. Estimating nonresponse bias in mail surveys. J. Mark. Res. 1977, 14, 396-402. [CrossRef]

34. Colbeck, C.L. How female and male faculty with families manage work and personal roles. In The Balancing Act: Gendered Perspectives in Faculty Roles and Work Lives; Stylus Publishing: Sterling, VA, USA, 2006; pp. 31-50.

35. Ziker, J.P.; Wintermote, A.; Nolin, D.; Demps, K.; Genuchi, M.; Meinhardt, K. Time distribution of faculty workload at Boise State University. In Proceedings of the Undergraduate Research and Scholarship Conference at Boise State University, Boise, ID, USA, 21 April 2014

36. Harrell, F.E., Jr.; Dupont, M.C. Hmisc: Harrell Miscellaneous, R Package Version 4.0-2. 2016. Available online: https: / / cran.r-project.org / package $=$ Hmisc (accessed on 24 June 2021).

37. García-Gallego, A.; Georgantzís, N.; Martín-Montaner, J.; Pérez-Amaral, T. (How) Do research and administrative duties affect university professors' teaching? Appl. Econ. 2015, 47, 4868-4883. [CrossRef]

38. Hastie, T.; Tibshirani, R.; Friedman, J. The Elements of Statistical Learning. Data Mining, Inference and Prediction, 2nd ed.; Springer: New York, NY, USA, 2009.

39. Vardi, I. The impacts of different types of workload allocation models on academic satisfaction and working life. High. Educ. 2009, 57, 499-508. [CrossRef]

40. Barrett, L.; Barrett, P. Women and academic workloads: Career slow lane or cul-de-sac? High. Educ. 2011, 61, 141-155. [CrossRef]

41. Myers, K.R.; Tham, W.Y.; Yin, Y.; Cohodes, N.; Thursby, J.G.; Thursby, M.C.; Schiffer, P.; Walsh, J.T.; Lakhani, K.R.; Wang, D. Unequal effects of the COVID-19 pandemic on scientists. Nat. Hum. Behav. 2020, 4, 880-883. [CrossRef]

42. King, M.M.; Frederickson, M.E. The Pandemic Penalty: The gendered effects of COVID-19 on scientific productivity. Socius 2021, 7, 23780231211006977. [CrossRef]

43. Witteman, H.O.; Haverfield, J.; Tannenbaum, C. COVID-19 gender policy changes support female scientists and improve research quality. Proc. Natl. Acad. Sci. USA 2021, 118. [CrossRef] 